\title{
School Counselors Help Build Resilience After Natural Disaster
}

\author{
Nisha Warbington, PhD, LPC-S, NCC, \\ Kelly Owenby, PhD, LPC \\ Hannah Brady, MA \\ Duana Bassham Shears, DBA \\ Jasmine Burton \\ Kourtni Strong \\ The University of West Alabama, United States
}

URL:http://dx.doi.org/10.19044/ejes.s.v6a4

\begin{abstract}
Natural disasters affect large numbers of children and youth in communities around the world. Unlike other crises, natural disasters impact entire communities, including the students and educators alike. These critical situations cause physical, emotional, academic, and psychological issues for those impacted. Educators, especially school counselors, often become a source of support for students and families. Providing support to students after a natural disaster is one protective factor that school counselors can provide that can help the students build resilience. Interviews were conducted to explore the lived experienes of school counselors who had experienced a natural disaster in their community and/or school. A dozen school counselors were contacted via email asking for their participation. Seven counselors participated in the interview. The school counselors interviewed all believed that experiencing the disaster with their students helped them provide more meaningful aftercare and all experienced some level of vicarious trauma or stress. All seven interviewees believed their personal experience of the natural disaster helped them to provide support to their students in a more empathic way.
\end{abstract}

Keywords: Building resilience, natural disaster, school counselor, vicarious traumatization, providing support.

\section{Introduction:}

Natural disasters impact millions of lives each year around the globe. While the media and general population tend to focus on the physical loss and 
devastation, the effects of natural disaster go beyond that and include emotional, psychological, and academic effects (American Psychological Association, 2019). Because many of those affected are children and youth, schools often become the staging area for providing support for the range of services required as communities heal (Coombe et al., 2015; Pfefferbaum et al., 2014). As a result, school counselors are frequently called to the forefront to provide support to those families and children. The support these families and children receive from the school and educators can play a vital role in helping these individuals build resilience after a natural disaster (Dias \& Cadime, 2017).

\section{Background:}

The rise in school violence is alarming and has triggered policymakers and educators to take action by changing policies to increase the safety of our children in school (DeMitchell \& Rath, 2019). There is no doubt that violence in our schools needs to be addressed; however, school violence is not the only trauma or crisis our children face. According to Dyregrov, Yule, and Olff (2018), natural disasters are on the rise as a result of climate change. In 2016, worldwide, 342 reported natural disasters caused 8,733 deaths, affecting 569.4 million people, and caused US\$154 billion damages (Guha-Sapir, Hoyois, Wallemacq, \& Below, 2017). It is estimated that approximately 175 million children per year will be affected by natural disasters (Codreanu, Celenza, \& Jacobs, 2014). For American youth, approximately 14 percent will experience a disaster during their childhood (Self-Brown, Lai, Thompson, McGill, \& Kelley, 2013).

When disaster strikes, communities tend to gather seeking support and comfort from people and places that are familiar. Schools are often one of the first and most central locations of relief operations (Coombe et al., 2015; Pfefferbaum et al., 2014). As a result, school staff, more specifically educators and school counselors, end up playing a vital part in the recovery process (Coombe et al., 2015; Pfefferbaum et al., 2014). The school, serving as a core for relief efforts, is often used as a primary access point for mental health services because these services can be delivered in schools without the stigma commonly associated with mental health interventions, and parents and families know and generally trust school personnel and processes (Coombe et al., 2015; Pfefferbaum et al., 2014). As a result, educators and especially school counselors, are vital participants in providing post-disaster services (Coombe et al., 2015; Pfefferbaum et al., 2014).

The American School Counselor Association (ASCA) clearly identifies the role and duties of a school counselor through the use of position statements. One position statement specific to crisis situations such as a natural disaster states "the professional school counselor's primary role is to facilitate 
planning, coordinate response to, and advocate for the emotional needs of all persons affected by the crisis/critical incident by providing direct counseling service during and after the incident" (2007, para. 5, as cited by Studer and Salter, 2010). Based on this statement, it is evident that school counselors are not only responsible but professionally required to respond to the needs of the students in the aftermath of a natural disaster. Given the estimated number of children expected to be affected by a natural disaster in any given year and considering the importance school counselors play in providing post-disaster services, school counselors need to understand ways in which they can help children and families cope with the adversity of a natural disaster and build resilience.

\section{Literature Review}

\section{Impact of Natural Disasters on Children}

Natural disasters include all types of severe weather that pose a significant threat to human health and safety such as winter storms, floods, tornadoes, hurricanes, earthquakes, wildfires, or any combination of these events (Homeland Security, 2018). Natural disasters affect everyone, and the result of natural disasters can range from physical injuries or death to emotional and psychological problems (American Psychological Association, 2019). The overall effects of any natural disaster can be long-lasting.

According to Codreanu, Celenza, and Jacobs (2014), approximately 5$43 \%$ of children who experience a natural disaster will experience posttraumatic stress disorder (PTSD). Long-term reactions include unpredictable emotions, flashbacks, strained relationships, and even physical symptoms like headaches or nausea. (American Psychological Association, 2019). Children may also experience changes in appetite, revert to developmentally inappropriate behaviors like bed-wetting or thumb-sucking, develop sleep issues, and exhibit psychosomatic issues (American Psychological Association, 2019). Many children experience depression, anxiety, as well as other mental health disturbances (Codreanu, Celenza, \& Jacobs, 2014). When children experience a natural disaster, their reaction include a range of internalizing (e.g., depression and anxiety) and externalizing (e.g., aggression, disruptive behavior, and conduct problems) behavioral problems (Rubens, Felix, \& Hambrick, 2018). These long-lasting issues often require the support of trained professionals.

The impact of natural disaster on children does not stop at mental health. Children's education is also impacted (Kousky, 2016). When children experience a crisis, there is the potential for impairment in problem-solving abilities and academic growth to occur (Studer \& Salter, 2010). School attendance may decrease, and mental health symptoms may directly impact academic performance (Kousky, 2016). As school counselors attempt to help 
students cope with the aftermath of a natural disaster, school counselors need to consider ways in which they can help students build resilient. School counselors also need to consider ways in which they can help themselves cope with the trauma of the natural disaster.

\section{Vicarious Trauma}

Natural disasters are associated with weather events (Homeland Security, 2018). Some weather events are extremely isolated as with some tornadoes or localized flooding while other weather events are more widespread as with hurricanes, large tornadoes, wildfires, or earthquakes. Depending upon the size of the area impacted by the natural disaster, it is feasible that the school counselor is experiencing dual effects; primary effects from facing the disaster personally, as well as effects experienced vicariously by counseling students who have also been affected (Lambert \& Lawson, 2013).

Vicarious trauma, sometimes referred to as compassion fatigue, secondary traumatic stress, or secondary victimization, is described by the American Counseling Association (n.d.) as the "emotional residue" that plagues the counselors as they listen to the pain and distress the client or student has endured. Vicarious trauma is defined as a state of tension or a preoccupation with the stories or trauma experienced by clients (American Counseling Association, n.d.). Though the school counselors impacted by a natural disaster are likely facing personal crises, they are likely to put off their own needs to counsel students (Trippany, Kress, \& Wilcoxon, 2004). The indirect exposure imposed upon the school counselor by the students and staff seeking counseling who were impacted by the natural disaster can affect the school counselor's wellbeing (Trippany, Kress, \& Wilcoxon, 2004). Trippany, Kress, and Wilcoxon (2004) report mental health effects due to vicarious trauma can include disruptions to memory and belief systems as well as a change in the counselor's cognitive schema of identity. Trippany, Kress, and Wilcoxon (2004) also indicate that vicarious trauma is often associated with burnout or countertransference.

In situations like natural disasters where there is a high degree of stress, it is important for the school counselor to step back and assess their own wellbeing in order to remain effective and mentally healthy (Barjon, 2008). The American Counseling Association Code of Ethics (2014) actually requires the counselor to practice self-care strategies. If the school counselor does not engage in self-care, their ability to provide support and help their students cope and build resilience will be negatively impacted. Successful counselors are driven by empathy, but such drive can lead to emotionally taking on the client or student's issues, and can therefore harm the counselor. Since driving ethics 
require the counselor maintain self-care (ACA, 2014), experiencing burnout and countertransference put the counselor at risk of doing harm to the client.

\section{Building Resilience}

One question that has perplexed those in the helping profession for decades is "why do some individuals seem to overcome and do well when faced with adversity and others do not?' (Arditti, 2015). The answer to this question seems to be resilience. According to Walsh (2016), resilience is the ability to withstand and rebound from crisis and prolonged adversity. If resilience is the answer, then the next question would be 'why do some individuals seem to be more resilient than others?' This is a question that has been researched by scholars for decades, and the most agreed-upon answer is that the degree of resilience depends upon the number of protective factors an individual possesses or experiences (Glantz \& Johnson, 2002). According to Dias and Cadime (2017), protective factors are individual characteristics or external conditions that help people cope with adversity. Some individual characteristics include perseverance, determination, self-efficacy, creativity, intelligence, and self-awareness (Dias \& Cadime, 2017; Glantz \& Johnson, 2002). Some external conditions include family support, good interpersonal relations, teacher and school support, and community relationships and resources (Dias \& Cadime, 2017; Glantz \& Johnson, 2002). The impact of teacher and school support as a protective factor needs to be explored as oneway school counselors can help children be resilient in the aftermath of a natural disaster.

As with many traumatic experiences, the needs of natural disaster survivors are unique, and the response efforts of helping professionals need to be specific and well informed (Boyd, 2016). Many survivors of natural disaster need to regain a sense of control over their lives (Boyd 2016). In the aftermath of a natural disaster, many individuals are not ready or willing to talk about their feelings, thoughts, or experiences. (Boyd, 2016). One way helping professionals can assist survivors in regaining control in their lives is to be aware of and respectful of individuals lack of desire to talk about the event (Boyd, 2016). According to Boyd (2016), supportive listening and not feeling judged by the helping professional are two significant post-disaster interventions; however, many times disasters present situations that are far beyond anything many counselors/helping professionals have ever experienced making supportive listening and unintentional non- judgmental behavior easier said than done. Fortunately, or maybe, unfortunately, school counselors have the upper hand in their ability to provide these two essential post-disaster interventions to their students. 


\section{Interviews}

Interviews were conducted as a part of this project but were not done as part of a formal study. The authors did not seek IRB approval, did not use a specific research design, nor use a formal data analysis tool. Interviews were conducted simply to explore lived experiences and provide support for current literature.

\section{Participants}

The authors of this article identified colleagues who were professional school counselors or counseling interns at the time of a natural disaster. The authors attempted to identify school counselors or counseling interns from a variety of different disasters in various parts of the United States. A dozen school counselors who had been working in the schools at the time of a natural disaster were contacted by email and asked to respond to a series of questions. . Five counselors provided email responses and two counselors completed a phone interview.

\section{Procedure}

One author was designated as the individual who was going to conduct the interviews and informally analyze the content of the interviews. As an individual was identified, their name and contact information were given to the designated author. The interviews were conducted via email or telephone. Counselors were given the option to respond by phone interview or by email. The author designated to analyze the data collected from the interviews reviewed the answers to each question and identified common answers. Based on the common answers, the author made conclusions about the overall experiences of the counselors/interns interviewed.

Each counselor was asked to answer the following questions:

1. What natural disaster did you experience as a professional school counselor or school counseling intern?

2. How were you personally impacted?

3. How long ago did this occur?

4. Do you feel your personal experience with the natural disaster helped you provide support to your students and faculty?

5. If so, why do you think your own experience with the natural disaster helped you provide support?

6. Did you experience any vicarious trauma?

7. If so, how did you cope with it?

8. Did you notice any protective factors that helped your students with resilience in this disaster?

\section{Results}


Of the seven counselors who responded, two of them were involved in hurricanes and the other five in tornadoes. The various disasters occurred across almost two decades from 2000-2019. Counselors personal impact ranged from having area friends and family impacted to being at the school during the touch down of the tornado.

All counselors reported that their personal experiences shaped their professional experiences and helped them provide support in a more empathic way. The theme across answers was that there was certainly a level of vicarious trauma to watch their communities suffer, but that they gained great personal and professional satisfaction by being able to play a valuable role in the recovery process. Counselors all reported coping with the stresses through self-care practices and professional and personal support through colleagues, family, friends, and faith-based communities. Of the counselors represented in this study, none reported unhealthy coping skills.

One of our respondents, a veteran school counselor, had experienced an E5 tornado hitting her school in 2013. She was in the school along with two of her children when the tornado touched down. She stated, "my school was destroyed. Our community was decimated." She reported it was important that she walked through the disaster with her students. "I had empathy for our students and faculty because we endured it together. She noted that she saw an improvement in their anxiety levels by educating them in what causes tornadoes, letting them see her stay strong, being there for them when they were scared, by teaching them positive coping skills especially while using a program called Journey of Hope, created by Save the Children (personal communications, June 28, 2019).

Another respondent, a counseling intern at the time, also experienced a tornado in her school's area in 2019. She had previously experienced another tornado as a child and used those memories of her reactions from childhood as a catalyst to help her better relate to her students. She also drew from the professional guidance of her supervisors. She noted that the most important protective factor she observed was community involvement. She noted that those students who were able to be with sports teams, church groups, or other community activities appeared to adjust more easily. She also perceived a better transition for those students who were able to resume a "regular" schedule. The intern noted that she did struggle with vicarious stress, and found a few coping strategies helpful in keeping herself healthy. She practiced methods of self-care, kept a schedule in place, and made sure she limited the time she spent caring for others (personal communications, June 29, 2019).

Counselors reported that the students who already had a strong support network through family, friends, and community or faith-based groups seemed to quickly connect and begin to rebuild. They also noted how vital disaster relief agencies were in providing for physical, psychological, spiritual, and 
emotional needs, especially for those who did not have a strong network before the disaster.

While each circumstance was unique, all the counselors agreed that experiencing the disaster with their students helped them provide more meaningful aftercare. Counselors reported being able to model healthy emotions, help students build on their resiliency, remain calm, emphasize relationships, review or teach positive coping skills, teaching problem solving, and empathize and normalize feelings. School counselors also indicated that, while dealing with their own needs related to the natural disaster was sometimes stressful, serving their students helped them gain a sense of fulfillment and professional accomplishment.

\section{Conclusion}

Children and youth are not immune to the after-effects of natural disasters. The number of school-aged children impacted by natural disasters each year is significant, and therefore, the support needed to help with the post-disaster needs is significant. Since school communities, and especially school counselors, are often the most logical access point for services, school counselors have an essential responsibility to disaster victims. School support is one factor that helps to build resilience, and it seems as though school counselors who have personally experienced the same natural disaster as the students seem to feel as though they are equipped to provide more empathetic support. When dealing with a natural disaster, counselors are often dealing with their personal reactions to the crisis in addition to their professional response. While this could cause additional stress, those that were interviewed did not feel that it took away from their professional abilities but instead provided them with an opportunity to give back to their community and students.

\section{References:}

1. American Counseling Association (2014). 2014 ACA code of ethics. Alexandria, VA: American Counseling Association.

2. American Counseling Association. (n.d.). Vicarious Trauma[PDF]. American Counseling Association.

3. American Psychological Association. (2019). Managing traumatic stress after a tornado. Retrieved from https://www.apa.org/helpcenter/tornadoes

4. Arditti, J. A. (2015). Situating Vulnerability in Research: Implications for Researcher Transformation and Methodological Innovation. The Qualitative Report, 20(10), 1568-1575. Retrieved from https://nsuworks.nova.edu/tqr/vol20/iss10/2 
5. Barjon, C. A. (2008. The impact of hurricane katrina on public school counselors and their delivery of responsive services. Unpublished doctoral dissertation. University of New Orleans.

6. Boyd, B. (2016). Counseling survivors of disaster. Counseling Across Cultures $7^{\text {th }}$ edition Chapter 16. Thousand Oaks, California: SAGE Publications, Inc.

7. Codreanu T. A., Celenza A., \& Jacobs I. (2014). Does disaster education of teenagers translate into better survival knowledge, knowledge of skills, and adaptive behavioral change? A systematic literature review. Prehospital and Disaster Medicine, 29(6), 1-3.

8. Coombe, J., Mackenzie, L., Munro, R., Hazell, T., Perkins, D., \& Reddy, P. (2015). Teacher-mediated interventions to support child mental health following a disaster: A systematic review. PLOS Currents Disasters. $\quad$ Retrieved from https://doi.org/10.1371/currents.dis.466c8c96d879e2663a1e5e274978 $\underline{965 d}$

9. DeMitchell, T. A., \& Rath, C. C. (2019). Armed and Dangerous -Teachers? A Policy Response to Security in Our Public Schools. Brigham Young University Education \& Law Journal, 2019(1), 63-93. Retrieved from https://search-ebscohostcom.libauth.purdueglobal.edu/login.aspx?direct=true $\& \mathrm{db}=\mathrm{tfh} \& \mathrm{AN}=1$ 35589019\&site $=$ ehost-live

10. Dias, P. C., \& Cadime, I. (2017). Protective factors and resilience in adolescents: The mediating role of self-regulation. Psicología Educativa, 23(1), 37-43. https://doi.org/10.1016/j.pse.2016.09.003

11. Dyregrov, A., Yule, W., \& Olff, M. (2018, August 15). Children and natural disasters. Retrieved from https://www.ncbi.nlm.nih.gov/pmc/articles/PMC6095022/

12. Glantz, M. D., \& Johnson, J. L. (2002). Resilience and Development: Positive Life Adaptations. New York: Springer. Retrieved from https://search-ebscohost com.libauth.purdueglobal.edu/login.aspx?direct=true \&db=nlebk\&A $\mathrm{N}=66717 \&$ site $=$ eds-live

13. Guha-Sapir, D., Hoyois, P., Wallemacq, P., \& Below, R. (2016). Annual disaster statistical review 2016: The numbers and trends. Brussels, Belgium: Centre for Research on the Epidemiology of Disasters. Retrieved from https://www.emdat.be/sites/default/files/adsr_2016.pdf

14. Homeland Security (2018). Natural disasters. Retrieved from https://www.dhs.gov/natural-disasters 
15. Kousky, C. (2016). Impacts of Natural Disasters on Children. Future of Children, 26, 1. Retrieved from https://eric.ed.gov/?id=EJ1101425.pdf

16. Lambert, S. F., \& Lawson, G. (2013). Resilience of Professional Counselors Following Hurricanes Katrina and Rita. Journal of Counseling \& Development,91(3), 261-268. doi:10.1002/j.15566676.2013.00094.x

17. Pfefferbaum, B., Sweeton, J. L., Nitiéma, P., Noffsinger, M. A., Varma, V., Nelson, S. D., \& Newman, E. (2014). Child disaster mental health interventions: Therapy components. Prehospital Disaster Medicine, $29(5)$ 494-502. https://doi.org/10.1017/S1049023X14000910

18. Rubens, S. L., Felix, E. D., \& Hambrick, E. P. (2018, June). A MetaAnalysis of the Impact of Natural Disasters on Internalizing and Externalizing Problems in Youth. Retrieved from https://www.ncbi.nlm.nih.gov/pmc/articles/PMC6055700/

19. Self-Brown, S., Lai, B. S., Thompson, J. E., McGill, T., \& Kelley, M. L. (2013). Posttraumatic stress disorder symptom trajectories in Hurricane Katrina affected youth. Journal of Affective Disorders, 147(1-3), 198-204. https://doi.org/10.1016/j.jad.2012.11.002

20. Studer, J. R., \& Salter, S. E. (2010). The role of the school counselor in crisis planning and intervention. Retrieved from https://www.counseling.org/resources/library/VISTAS/2010-VOnline/Article 92.pdf

21. Trippany, R. L., White Kress, V. E., \& Wilcoxon, S. A. (2004). Preventing vicarious trauma: what counselors should know when working with trauma survivors. Journal of Counseling \& Development, 82(1), 31-37. Retrieved from http://search.ebscohost.com.ezproxy.uwa.edu/login.aspx?direct=true $\& \mathrm{db}=\mathrm{ccm} \& \mathrm{AN}=108035215$ \&site $=$ eds-live

22. Walsh, F. (2016). Strengthening Family Resilience $3^{\text {rd }}$ edition. New York, New York: The Guildford Press. 